\title{
Attitude of pregnant women in south western Nigeria towards caesarean section as a method of birth
}

\section{Adenike Funmilola Faremi ${ }^{1}$, Olabisi Fatimo Ibitoye ${ }^{2}$, Matthew Idowu Olatubi ${ }^{3}$, Patrcia N. Koledoye ${ }^{4}$, Gbemisola Bolanle Ogbeye ${ }^{5}$}

\author{
${ }^{1}$ Department of Nursing Science, Obafemi Awolowo University, Ile-Ife, Osun State, Nigeria \\ ${ }^{2}$ School of Midwifery, Akure, Ondo State, Nigeria \\ ${ }^{3}$ Ondo State School of Nursing, Akure, Ondo State, Nigeria \\ ${ }^{4}$ State Specialist Hospital Akure, Ondo State, Nigeria \\ ${ }^{5}$ Health Centre, Federal University of Technology, Akure, Ondo State, Nigeria
}

Received: 1 August 2014

Accepted: 9 August 2014

\section{*Correspondence:}

Mr. Matthew Idowu Olatubi,

E-mail: omoolatubi@yahoo.com

(C) 2014 Faremi AF et al. This is an open-access article distributed under the terms of the Creative Commons Attribution Non-Commercial License, which permits unrestricted non-commercial use, distribution, and reproduction in any medium, provided the original work is properly cited.

\begin{abstract}
Background: Choice of the method of birth is an essential decision for pregnant women and the spouse. This choice is sometimes based on a number of factors. This study assesses knowledge of pregnant women about caesarean section, their attitude towards it and level of acceptance of the methods of birth among women.

Methods: This descriptive study was carried out in a government owned hospital in south western Nigeria. Respondents were selected using accidental sampling techniques. Questionnaire whose validity and reliability has been previously ascertained was the instrument used for data collection. Data generated was analysed using SPSS.

Results: Results show that $17.1 \%$ of the women have good knowledge of caesarean section as a method of birth. Majority of the respondents agreed that vaginal delivery creates more mother-baby relationship than caesarean section. $69.5 \%$ of the respondents agreed that caesarean section is preferable to vaginal delivery as the pain in vaginal delivery is usually unpleasant, 66.0\%) disagreed that babies born through caesarean section are more healthy than their other counterpart that are born through vaginal delivery. Only $6.9 \%$ accept caesarean section.

Conclusions: Mothers should therefore be educated on the process involved in caesarean birth and the advantage of this method of birth over other birth method.
\end{abstract}

Keywords: Attitude, Acceptance, Caesarean section, Knowledge, Methods of birth

\section{INTRODUCTION}

For a healthy women population, the choice of delivery option is an important decision. Expectant parents make many choices which usually include site for delivery (hospital, birth centre, or home), and the choice between spontaneous vaginal delivery and caesarean section. ${ }^{1}$ Over time caesarean section rates has been on the increase in the whole world. ${ }^{2}$ Both developed and developing nations of the world have their own share of this increase. ${ }^{3}$
Epidemiological studies in Brazil and Chile have shown that there is higher caesarean section rate among women who have a higher level of education. ${ }^{4}$ In some African, increase in the rate of caesarean section have been documented; Ghana ${ }^{5}$ and Nigeria. ${ }^{6}$ However there is a broadly held belief that West African women have an aversion for caesarean section delivery. ${ }^{7}$ Maternal knowledge and occupation has also been seen to influence the attitude of women towards mode of delivery. Many studies have proven women preference for vaginal deliveries over surgical delivery. ${ }^{8-15}$ Although majority of caesarean sections are emergency caesarean 
sections especially in developing nations there is also a noticeable increase in the rate of elective surgery of late probably due to increase level of knowledge of women, improvement in medical practice and women higher level of education. It is important to note that elective emergency caesarean section is known to be associated with more maternal and newborn morbidity than planned vaginal birth. ${ }^{16-19}$ In a study carried out by Nira and colleagues to assess the attitude of women toward caesarean section in Nepal they found out that vaginal delivery was the preferred mode of delivery by $93 \%$ of the respondents while $7 \%$ preferred caesarean section as mode of delivery. ${ }^{3}$ Their reasons for these ranges from it been a natural process, been good for mother's health, safety to been an easy process.

Most of the women thought that caesarean delivery can cause long term ill effect on mother's health. All the women who preferred elective caesarean delivery initially said that they would rather opt for painless labour and vaginal delivery if offered over caesarean section. Similarly Aziken, Omo-Aghoja, \& Okonofua submitted that inaccurate cultural perception about caesarean section delivery account for poor attitude of women towards caesarean section. ${ }^{20}$ Aali \& Motamedi reported that only one third of women demonstrate positive attitude towards caesarean delivery as against $95.5 \%$ for vaginal delivery in the same group of respondents. The study concluded no significant differences in attitude and knowledge scores according to women's levels of education. $^{21}$

It is not strange to hear many pregnant women ventilating wrong attitude towards caesarean section as an alternative method of birth. Especially in the developing countries like Nigeria, a number of women believe caesarean section is a last resort used to deliver a pregnant women of her baby, many will even say, been told that they are going to deliver their babies through caesarean section is like giving a death warrant. This attitude towards caesarean section influence women acceptance of the procedure and resulted in psychological depression that women and their family usually experience when been told that their baby will be delivered through caesarean section, this will have adverse effect on the outcome of the procedure.

\section{Research objectives}

This study seeks to:

1. Assess the level of knowledge of women about caesarean section.

2. Determine the attitude of women towards caesarean section.

3. Assess the level of acceptance of caesarean section as a method of birth among women.

\section{METHODS}

This study adopted descriptive design to assess the attitude of women towards caesarean section as an alternative method of birth. The study will be conducted at state specialist hospital, Akure Ondo State. This is a government owned hospital that provides secondary level of health care to the people. Respondents were selected using accidental sampling techniques; only pregnant women that were met in the clinic during their ante natal clinic were recruited to participate in the study. Participation was optional. Thumb's rule was used to determine sampling size. i.e. at least $30 \%$ of the hospital monthly ante natal clinic attendance. The average monthly ante natal attendance in the hospital is 410 .

Questionnaire was the instrument used for data collection. The questionnaire was developed from literature review; it is a self-administered structured likert-type questionnaire. The questionnaire was divided into three (3) sections. Section A asked questions about socio demographic characteristics of the respondents, section $\mathrm{B}$ asked question about the knowledge of the respondents about caesarean section while section $\mathrm{C}$ seek to assess respondents attitude towards caesarean section as an alternative method of delivery. The validity of the questionnaire was established through face and content validity criteria. The developed questionnaire was given to experts in the field of nursing, reproductive health, sociology and demography and social statistics for thorough scrutiny. Each item on the instrument was examined for content clarity, scope and relevance to the study.

The reliability of the instrument was established by testretest method. The instrument was administered on twenty pregnant women attending ante natal clinic in mother and child hospital Akure, Ondo state twice with 3 weeks interval. The result was correlated using Spearman rho correlations with correlation coefficient of 0.81 . This result shows that the instrument is highly reliable. Permission to conduct the study was obtained from the authority of state specialist hospital Akure. Only pregnant women that consented to participate in the study were recruited. Participation was made voluntary and the right of any participant to withdraw from the study at any stage without any adverse consequences on the care they receive in the clinic was stressed to them. Data collected were stored in a pass worded folder in the personal computer of one of the respondents. Every information provided was used only for the study.

Data generated were analyzed using Statistical Package for Social Service Solution (SPSS), version 16. Correct answer on the knowledge question of the questionnaire attract 2 marks, incorrect answer attract 1 mark. Total cumulative score of $70 \%$ and above is regarded as good knowledge, $50 \%$ to $69 \%$ fair knowledge while a score of $49 \%$ and below is regarded as poor knowledge of caesarean birth. 


\section{RESULTS}

Results show that the mean age of the women that participated in the study was 31.64 years with standard deviation of 6.13 and range of 29.00. Level of education of the women shows that $38.9 \%$ had tertiary education, $28.6 \%$ secondary education, $30.5 \%$ primary education while only 4 respondents $(2.0 \%)$ did not have any formal education. More Christian and Yoruba participated in the study as compared to other tribe or religious group. Sixty six $(32.5 \%)$ were single while $67.5 \%$ were married.

Obstetric history of the respondents shows that vast majority (75.9\%) had their last baby through normal vaginal delivery, $5.9 \%$ through caesarean section and $3.4 \%$ through assisted vaginal delivery. If respondents were to choose method of birth, $85.7 \%$ will choose vaginal delivery, $8.9 \%$ caesarean section while $5.4 \%$ said they did not have preference for any method, $42.9 \%$ will agree if given the option of caesarean section for their next delivery, 45.3 will disagree while $11.8 \%$ were undecided about what their response will be. The mean number of pregnancy that the respondents had carried shows 2.69 , while number of children shows mean of 2.30 .

Respondent perceived factors that promote the rate of caesarean section shows that $80.3 \%$ agreed to advancing age, $60.1 \%$ agreed to socioeconomic factors, $22.2 \%$ disagree while $17.7 \%$ were undecided. About half of the respondents $(45.8 \%)$ agreed that reduced parity can be factors $30.0 \%$ were undecided while $24.1 \%$ disagreed. Results also showed that $69.5 \%$ opined that improvement in surgical techniques was responsible for increase in the rate of caesarean section, 23.2 were undecided while 7.4 disagreed.
The Table 1 presents the level of knowledge of the women toward caesarean section as a method of birth. Result from the table shows that only $17.2 \%$ of the respondents have good knowledge of caesarean section, $36.0 \%$ have fair knowledge, while majority, (46.8\%) have poor knowledge of caesarean section.

Table 1: Knowledge of women about caesarean section.

\begin{tabular}{|lll|}
\hline Knowledge & Frequency & Percentage \\
\hline Poor knowledge & 95 & 46.8 \\
\hline Fair knowledge & 73 & 36.0 \\
\hline Good knowledge & 35 & 17.2 \\
\hline Total & 203 & 100.0 \\
\hline
\end{tabular}

Results from this study also show that $60.1 \%$ of the respondents believed that pain in caesarean section is less severe as compared to pain in vaginal delivery. Most of the respondents $(40.9 \%)$ believed that maternal morbidity is not more associated with caesarean section than vaginal delivery, $34.5 \%$ believed that maternal morbidity is more frequent in caesarean section than vaginal delivery. Result also shows that many of the respondents $(43.3 \%)$ opined that infections are more common among women delivered with caesarean section than vaginal delivery. Majority of the respondents $(77.8 \%)$ opined that method of birth does not dictate the level of intelligent of the baby while $12.8 \%$ said baby born through caesarean section are more intelligent than their other counterpart through vaginal delivery. the table also revealed that many of the women $(58.6 \%)$ believe that bleeding in caesarean section is less severe than normal vaginal delivery.

Table 2: Respondents attitude towards caesarean section.

\begin{tabular}{|llll|}
\hline Vaginal delivery creates a more affectionate mother-baby relationship & Agreed & Undecided & Disagree \\
\hline Caesarean section is preferable in the absence of economic problems & $126(62.1)$ & $22(10.8)$ & $55(27.1)$ \\
\hline Caesarean section is preferable as pain of vaginal delivery is unpleasant & $84(41.4)$ & $48(23.6)$ & $71(35.0)$ \\
\hline Babies born by caesarean section are healthier that those delivered by vaginal delivery & $141(69.5)$ & $12(5.9)$ & $50(24.6)$ \\
\hline $\begin{array}{l}\text { Having a birth plan (written outline of preferences for labour and birth) is a good idea } \\
\text { for a pregnant women. }\end{array}$ & $145(71.4)$ & $21(10.3)$ & $37(18.2)$ \\
\hline $\begin{array}{l}\text { It is a woman's right to choose a caesarean section for herself, even if there are no } \\
\text { medical reasons to have it }\end{array}$ & $130(64.0)$ & $25(12.3)$ & $48(23.6)$ \\
\hline $\begin{array}{l}\text { Compared with vaginal birth, caesarean section prevents bladder problems (such as } \\
\text { urinary frequency, urgency or loss of urine) in the future. }\end{array}$ & $120(59.1)$ & $39(19.2)$ & $44(21.7)$ \\
\hline $\begin{array}{l}\text { Compared with vaginal birth, caesarean section prevents future sexual problems for } \\
\text { the mother. }\end{array}$ & $101(49.8)$ & $25(12.3)$ & $77(37.9)$ \\
\hline Compared with vaginal birth, caesarean section is more convenient for mothers. & $88(43.3)$ & $43(21.2)$ & $72(35.5)$ \\
\hline Caesarean section is a less painful method of delivery than vaginal birth. & $170(83.7)$ & $7(3.4)$ & $26(12.8)$ \\
\hline Compared with vaginal birth, caesarean section is safer for the baby. & $116(57.1)$ & $41(20.2)$ & $46(22.7)$ \\
\hline For women, Caesarean section is as safe as vaginal birth. & $142(70.0)$ & $8(3.9)$ & $53(26.1)$ \\
\hline
\end{tabular}


Table 2 present the attitude of women towards caesarean section, majority of the respondents $(62.1 \%)$ agreed that vaginal delivery creates more mother-baby relationship than caesarean section. $69.5 \%$ of the respondents agreed that caesarean section is preferable to vaginal delivery as the pain in vaginal delivery is usually unpleasant. Findings from the study also show that many of the women $(66.0 \%)$ disagreed that babies born through caesarean section are more healthy than their other counterpart that are born through vaginal delivery while $12.8 \%$ agreed to that assertion. Many of the women $(64.0 \%)$ opined that women have the right to choose caesarean section even if there are no any medical reasons for that. Three out of every five women said caesarean section prevents bladder problem in the future, $49.8 \%$ agreed that caesarean section prevents future sexual problems for the mother. Vast majority $(83.7 \%)$ said caesarean section is less painful for the mother when compared to vaginal delivery. on how convenient caesarean section is; $43.3 \%$ said it is more convenient, $21.1 \%$ were undecided while $35.5 \%$ disagreed. Seventy percent of the women believe caesarean section is safer for the women and $57.1 \%$ agreed that it is safer for the baby as a method of birth.

Results from the study as shown in Table 3 shows, that $93.1 \%$ of the respondents agreed that vaginal delivery is a natural and acceptable mode of delivery. Larger percentage of the respondent $(92.6 \%)$ agreed that seeing once baby immediately after delivery as it is the usual practice in vaginal delivery that is absent in caesarean section delivery is pleasurable to the mother, a good number of the mothers $(79.3 \%)$ also agreed that mothers regain their health status faster after vaginal delivery than caesarean section. about the outcome $65.5 \%$ of the mother believe that vaginal delivery has more pleasant outcome than caesarean section, while $17.2 \%$ disagreed with this assertion. overwhelming majority of the mothers $(80.3 \%)$ opined that having vaginal delivery gives the woman confidence in her ability to give birth, while $59.1 \%$ of the women said any woman who deliver through caesarean section miss an important life experience.

Table 3: Respondent's perception of caesarean section.

\begin{tabular}{|llll|}
\hline Vaginal delivery is a natural and acceptable mode of delivery & $189(93.1)$ & $10(4.9)$ & $4(2.0)$ \\
\hline $\begin{array}{l}\text { Seeing the baby immediately after vaginal delivery is a pleasure } \\
\text { for the mother }\end{array}$ & $188(92.6)$ & $9(4.4)$ & $6(3.0)$ \\
\hline $\begin{array}{l}\text { Mothers regains her health status sooner after vaginal delivery } \\
\text { than caesarean section }\end{array}$ & $161(79.3)$ & $14(6.9)$ & $28(13.8)$ \\
\hline In terms of outcome, vaginal delivery is more pleasant & $133(65.5)$ & $35(17.2)$ & $35(17.2)$ \\
\hline $\begin{array}{l}\text { I believe that having a vaginal birth is a more empowering } \\
\text { experience than delivering by caesarean section }\end{array}$ & $143(70.4)$ & $20(9.9)$ & $40(19.7)$ \\
\hline $\begin{array}{l}\text { The most important thing in having a vaginal delivery is the } \\
\text { woman's own confidence in her ability to give birth }\end{array}$ & $163(80.3)$ & $10(4.9)$ & $30(14.8)$ \\
\hline $\begin{array}{l}\text { Women who deliver their baby by caesarean section miss an } \\
\text { important life experience }\end{array}$ & $120(59.1)$ & $26(12.8)$ & $57(28.1)$ \\
\hline $\begin{array}{l}\text { I believe that a woman recovers faster after a caesarean section } \\
\text { than after vaginal birth. }\end{array}$ & $51(25.1)$ & $19(9.4)$ & $133(65.5)$ \\
\hline
\end{tabular}

\section{DISCUSSION}

Findings of this study show that mean of the mothers attending ante natal clinic in state specialist hospital Akure was 31.64 years with standard deviation of 6.13. Study also found out that out two of every five woman attending ante natal clinic in the hospital had tertiary level of education while only four respondents did not have any formal education. This study also further established Yoruba and Christian's dominance of Akure where this study was carried out. It is important to note that one out of every three pregnant women that participated in this study were single i.e. they got pregnant out of wedlock, this will have tremendous implications on their family structure and the society in the future as this establish the increase in single parenthood in our society.

Overwhelming majority of the respondents had their last baby through normal vaginal delivery, which established women preference for normal vaginal delivery over caesarean section. This is in support of submissions of previous studies. ${ }^{8-15}$ They all reported that despite increase in the rate of caesarean section among women in their various study population, majority of the women still prefer normal vaginal delivery over caesarean section method during birth. 
Mothers' perceived factors that promote the increased rate of caesarean section include: advancing maternal age, socio-economic factors, reduced parity and improvement in surgical technique, this is consistent with assertions of Cunningham who opined that reasons suggested by mothers for the increase rates of caesarean delivery include advancing maternal age, socioeconomic factors, reduced parity and improvements in surgicaltechniques. ${ }^{22}$ Women knowledge of caesarean section shows that only few of the respondents have good knowledge of caesarean section, this is not strange in that many of them did not like the method.

Many of the respondents' perceived reduced pain as one of the advantages of caesarean section; but they reported that caesarean section is associated with increased maternal morbidity and rate of infections. Most of the women believed that caesarean section does not affect the level of intelligence of the baby, it is however important to note that $12.8 \%$ of the respondents opined that babies born through caesarean section are more intelligent than their counterparts through vaginal delivery. Scientific discovery however, have not documented any relationship between caesarean section and level of intelligence of the baby; except that when instrumental deliveries were done when vaginal delivery is not properly managed it can lead to brain damage in the baby which can affect the level of the child's intelligence in the future.

Attitude of the mothers towards methods of birth shows that majority believed that vaginal delivery create more mother-baby friendly relationship than caesarean section; good number will prefer caesarean section because of the reduction in the level of pain as compared to vaginal delivery. Mothers perceived that babies born through caesarean section are healthier and that they have the right to choose caesarean section over normal vaginal delivery even if it is not medically indicated. A good number of the respondents perceived that caesarean section prevent various problems for the women in the future, these according to them include bladder related problems and sexual problems. On the convenience of CS method of birth, two out of every five women believed that it is more convenient than vaginal delivery; $21.1 \%$ were undecided while the rest disagreed.

Almost all the respondents said vaginal delivery is natural and acceptable mode of delivery; and that seeing once baby immediately after delivery as it is the usual practice in vaginal delivery that is absent in caesarean section and delivery is pleasurable to the mother. They also viewed that mother regain their health status i.e. the go back to their pre pregnancy state of health faster and better in vaginal delivery as compared to caesarean section, therefore agreed that the outcome of vaginal delivery is more pleasant than caesarean section. It is therefore not strange that majority of the mothers submit that vaginal delivery gave the woman confidence in her ability to give birth and that a woman that does not have the opportunity of given birth through vaginal delivery misses as important life experience.

\section{Implication of the study}

This study shows that a good number of the women attending ante natal clinic in state specialist hospital Akure still have negative attitude towards caesarean section and their knowledge about this important method of delivery is still poor. It is therefore, not strange that a good number of the respondent did not like caesarean section as a method of birth. This study now implies that despite increase rate of caesarean section the acceptance is still low, it is therefore likely that majority of the mothers that undergo caesarean section do that because it is mandatory.

\section{Recommendation}

Based on the findings of this study, the following recommendations were made:

1. All women of reproductive age should be educated on caesarean section as a method of birth.

2. Teaching on caesarean section should be included in the Ante Natal health education.

3. Government should encourage caesarean section delivery by subsidizing the cost to encourage women to opt for this method of birth.

4. Right of women in choosing any preferred method of birth at any level of health care should always be respected.

\section{Suggestions for further study}

While this study established that many women still prefer normal vaginal delivery over caesarean section; this might however not be generalisable as it is only women that have undergone the two methods of delivery and did not opt for caesarean because it is the only available option but voluntarily choose to deliver through caesarean section that can objectively assess the two method of birth. Therefore, further study should be done among women that had had previous experience of the two methods of birth. This study was conducted among mothers attending ante natal clinic in one hospital, further study should be done in multiple hospital or even multistate study so that the result will be generalisable and better comparison can be made across religion and ethnicity.

\section{CONCLUSION}

This study found out that although the rate of caesarean section is on the high side the acceptance is still low possibly due to poor knowledge of the process and negative attitude towards it, it is therefore inferred that majority of women that undergo caesarean section do not 
like this method of birth, they probably opt for it because it is the only available option. Mothers should therefore be educated on the process involved in caesarean birth and the advantage of this method of birth over other birth method.

Funding: No funding sources

Conflict of interest: None declared

Ethical approval: The study was approved by the institutional ethics committee

\section{REFERENCES}

1. Klein MC, Kaczorowski J, Hearps SJ, Tomkinson J, Baradaran N, Hall WA, et al. Birth technology and maternal roles in birth: knowledge and attitudes of Canadian women approaching childbirth for the first time. J Obstet Gynaecol Can. 2011;33(6):598-608.

2. Rozenburg P. Evaluation of the caesarean section rate: a necessary progress in obstetrics. J Gynaecol Obstet Biol Reprod (Paris). 2004 Jun;33(4):279-89.

3. Nira S. Shrestha, Sumita Pradhan. On demand caesarean section: what's women's attitude? N J Obstet Gynaecol. 2007 Nov-Dec;2(2):12-5.

4. Behagus DP, Victoria CG, \& Barros FC. Consumer demand for caesarean section in Brazil: informed decision making patient choice, or social inequality? A population based birth cohort study linking ethnographic and epidemiological methods. Br Med J. 2002;(324):942-5.

5. Reproductive and Child Health Unit. Reproductive health strategic plan. In: RCHD, eds. Annual Report. Ghana: Public Health Division, Ghana Health Service; 2003: 23.

6. Oladapo OT, Sotunsa JO, Sule-Odu AO. A rise in caesarean birth rate in Sagamu, Nigeria: a reflection of changes in obstetric practice. J Obstet Gynaecol. 2004 Jun;24(4):377-81.

7. Awoyinka BS, Ayinde OA, Omigbodun AO. Acceptability of caesarean delivery to antenatal patients in a tertiary health facility in South West Nigeria. J Obstet Gynaecol. 2006 Apr;26(3):208-10

8. McGurgan P, Coulter-Smith S, O'Donovan PJ. A national confidential survey of obstetrician's personal preferences regarding mode of delivery. Eur J Obstet Gynaecol Reprod Biol. 2001;97:17-9.

9. Kwee A, Cohlen BJ, Kanhai HHH, Bruinse HW, Visser GHA. Caesarean section on request: a survey in the Netherlands. Eur J Obstet Gynecol Reprod Biol. 2004;113:186-90.

10. Osis MJD, Padua KS, Duarte GA, Souza TR, Faundes A. The opinion of Brazilian women regarding vaginal labour and caesarean section. Int $\mathbf{J}$ Gynaecol Obstet. 2001;75:S59-66.

11. Chong ESY, Mongelli M. Attitudes of Singapore women towards caesarean and vaginal deliveries. Int J Gynaecol Obstet. 2003;80:189-94.

12. Lee S, Khang Y, Lee M. Women's Attitudes toward mode of delivery in South Korea: a society with high caesarean section rates. Birth. 2004;31(2):108-16.

13. Donati S, Grandolgo MD, Andreozzi S. Do Italian mothers prefer caesarean delivery? Birth. 2003;30(2):89-93.

14. Aslam MF, Gilmour K, Fawdry RDS. Who wants a caesarean section? A study of women's personal experience of vaginal and caesarean delivery. J Obstet Gynaecol. 2003;23(4):364-66.

15. Gamble JA, Creedy DK. Women's preference for a caesarean section: incidence and associated factors. Birth. 2001;28(2):101-10.

16. Liu S, Heaman M, Joseph KS, Liston RM, Huang L, Sauve R, et al. Risk of maternal postpartum readmission associated with mode of delivery. Obstet Gynaecol 2005;105:836-42.

17. Liu S, Liston RM, Joseph KS, Heaman S, Sauve R, Kramer MS, et al. Maternal mortality and severe morbidity associated with low-risk planned cesarean delivery versus planned vaginal delivery at term. Can Med Assoc J. 2007;176:455-60.

18. Liston FA, Allen VM, O'Connell CM, Jangaard KA. Neonatal outcomes with cesarean delivery at term. Arch Dis Child Fetal Neonat Ed. 2008;93:F176-82.

19. Wax J, Cartin A, Pinette M, Blackstone J. Patient choice cesarean: an evidence-based review. Obstet Gynaecol Surv. 2004;59:601-16.

20. Aziken M, Omo-Aghoja L, Okonofua F. Perceptions and attitudes of pregnant women towards caesarean section in urban Nigeria. Acta Obstet Gynaecol Scand. 2007;86(1):42-7.

21. Aali BS, Motamedi B. Women's knowledge and attitude towards modes of delivery in Kerman, Islamic Republic of Iran. East Mediterr Health J. 2005;11(4):663-72.

22. Cunningham FC, Williams JW. Caesarean delivery. In: Cunningham FC, Williams JW, eds. William's Obstetrics. 20th ed. Stamford, Connecticut: Appleton \& Lange; 1997: 509-530.

DOI: $10.5455 / 2320-1770 . i j \operatorname{cog} 20140970$

Cite this article as: Faremi AF, Ibitoye OF, Olatubi MI, Koledoye PN, Ogbeye GB. Attitude of pregnant women in south western Nigeria towards caesarean section as a method of birth. Int J Reprod Contracept Obstet Gynecol 2014;3:709-14. 